\title{
Design Innovation and Validation of a Non-Electric Hearing Aid for Improved Usability
}

\author{
Poh Kiat $\mathrm{Ng}^{1}{ }^{*}$, Kian Siong Jee ${ }^{1}$, Li Wah Thong ${ }^{1}$ and Jian Ai Yeow ${ }^{2}$ \\ ${ }^{1}$ Faculty of Engineering and Technology, Multimedia University \\ ${ }^{2}$ Faculty of Business, Multimedia University \\ Melaka, Malaysia \\ *Corresponding author e-mail: pkng@mmu.edu.my
}

\begin{abstract}
This study aims to innovate and validate the design of a non-electric hearing aid for improved usability. Studies on conventional and existing hearing aids were carried out before the actual study on developing this non-electric hearing aid was done. The final product underwent a series of evaluations in order to verify its viability and usability. Conceptualisation, material selections and concept selections were carried out in order to select the most appropriate concept for this study. The material selection process ensures that the choice of material is appropriate for the specific requirements of the components to be achieved. Subsequently, a detailed cost analysis was carried out to ensure that the manufactured product would be affordable to the customers. Several experiments and tests were performed to evaluate the product's performance. Although a validated prototype for a non-electric hearing aid is in hand, future improvements on the fabricated product are still needed in order to ready the product for its future commercialisation phase.
\end{abstract}

Keywords: Ergonomics, Engineering design, hearing aid, non-electric

\section{Introduction}

Hearing loss has become one of the most common diseases in the world. This may be due to working environment, genetic problem and/or accident and can be categorized as conductive and sensorineural hearing loss [1]. With the help of a hearing aid, hearing impairment may be corrected.

A hearing aid is a sound-amplifying device that is able to assist patients with impaired hearing or hearing loss [2]. A hearing aid can be categorised into two different groups; electrical hearing aids and non-electric hearing aids. The electrical hearing aids can be further divided into bone conduction and air conduction hearing aids, with several different types for each category [3]. Nonelectric hearing aids, on the other hand, basically incorporate trumpet, speaking tube, hybrid device and bone-conduction device.

In the past few decades, there has been a major development on electrical hearing aids. However, it appears that there is not much development on the non-electric hearing aid. Under certain circumstances, there may be a time when a non-electric hearing aid is necessary, appropriate and more beneficial than the electrical hearing aid.

This project aims to design and fabricate an ergonomic nonelectric hearing aid. The product being designed needs to show a durable, sustainable and reliable characteristic. This helps to ensure that the product has quality due to its durability.

\section{Non-Electric Hearing Aids}

Non-electric hearing aids are also known as conventional or traditional hearing aids. Dillon stated that non-electric hearing aids were found in the year 1865 and had been extensively used during the era of acoustics development [4].

At the early stage of this era, people started to amplify sound using their bare hands. They held it in the form of a paw and put it behind the ears. This amplification method can be defined as the natural hearing aid [5]. As time passed by, different types of portable device had been invented. These devices include horn, trumpet, funnel, and conversation tube. Among them, the conversation tube showed the best performance in terms of sound amplification. Figure 1 shows the categories of non-electric hearing aids.

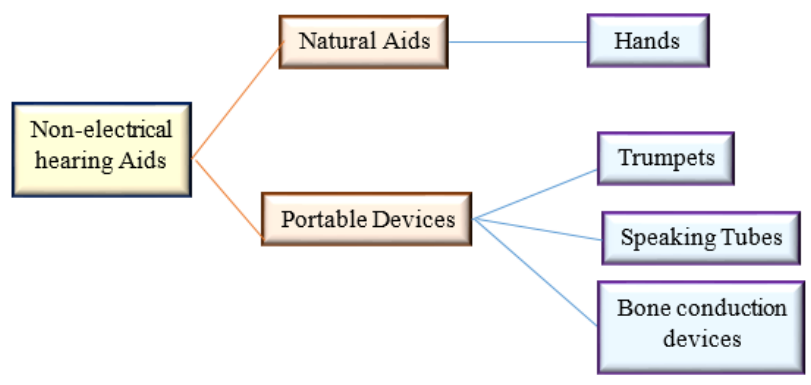

Figure 1: Categories of non-electric hearing aids 


\section{Importance of Non-Electric Hearing Aid}

It turns out that there is a need for non-electric hearing aids because they do show some features which are not obtainable by using electrical hearing aids. These features include environmental conditions, cost, and material maintenance. Figure 2 shows the importance of using non-electric hearing aids.

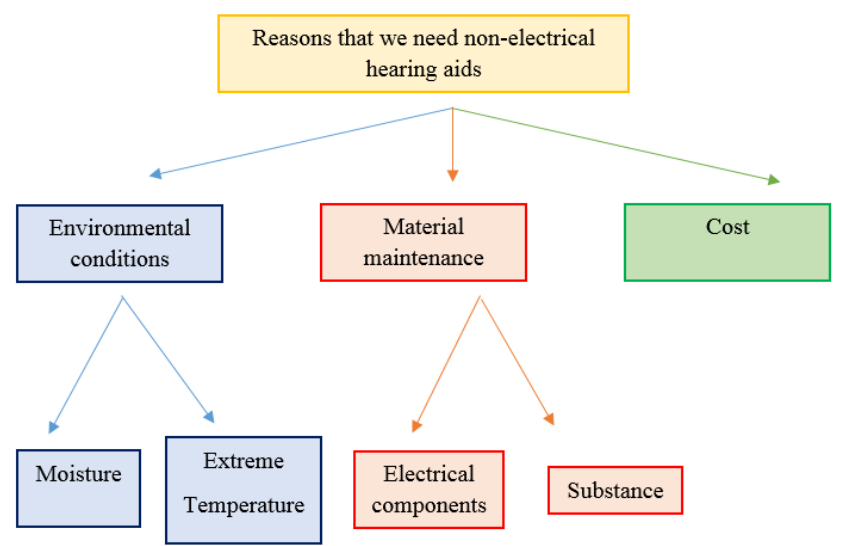

Figure 2: Importance of non-electric hearing aids

Electrical hearing aids have many advantages but they are not able to display certain characteristics of the non-electric hearing aids. Dr Ross stated that electrical hearing aids are not able to perform well under moisture and other conditions of extreme temperature [6]

For some countries including Malaysia, the humidity level is high Humidity causes the internal electronic components to become easily damaged. Other than moisture from the surrounding, moisture inside the outer ear can also cause electrical hearing aids to malfunction. Since there are no electronic components inside non-electric hearing aids, moisture will not affect their performance.

Some countries do have extreme temperature in their climate. For example, in China, daytime can exhibit extremely high-temperature of more than $40^{\circ} \mathrm{C}$. Temperature may drop gradually to $2 \sim 3{ }^{\circ} \mathrm{C}$ by night time. This great change of temperature can cause electrical hearing aids to malfunction because as temperature changes, air may condense and become water vapours, which in turn can also cause the components inside the electrical hearing aids to malfunction.

The battery equipped inside an electrical hearing aid needs to be changed gradually every few months (Ross, 1999). This can become inconvenient to the users, as the electrical components inside the electrical hearing aids may cause accidents. Apart from that, users also need to spend money to change the battery although cost is not an issue. Battery change is unnecessary if a non-electric hearing aid is used.

Electrical hearing aids may also contain non-electric parts such as a specialized ear wax mould. This needs to be cleaned every few months because it may change shape due to high or extreme temperature. This could cause the ear wax mould to deform and may cause discomfort to the users. Non-electric hearing aids actually eliminate this hassle because non-electric hearing aids do not need any sort of specialized ear wax mould to use.

According to Katherine Bouton, a good electrical hearing aid can easily cost $\$ 2000 \sim 6000$ [7]. This is rather expensive for most users and poses a great burden for many people. Other than that, hearing aids will not be covered by insurance unless the hearing loss was caused by a disease stated in the insurance policy.

Thus, a non-electric hearing aid is cheaper, despite lacking certain functions such as the ability to enable different listening modes. Low price is the greatest sales point for non-electric hearing aids.

\section{Conceptualisation}

Conceptualisation can be defined as a selection of an object, concepts or other entities which correlates to the objective of the project. In designing a non-electric hearing aid, conceptualization involves the selection of concepts that portrays the product's intended purpose, which is to amplify sound correctly and to provide convenience to users.

In the process of conceptualization, important aspects which need to be focused are the people, material and time [8]. The conceptualization process needs to ensure that all three different aspects are considered carefully to ensure profit.

\subsection{Concept 1: Wearable Speaking Tube}

The speaking tube shows the best performance on the amplification of sound compared to other types of non-electric hearing aids. However, the speaking tube is deficient in terms of its inconvenient weight. Therefore, certain features are necessary to counter the disadvantages of the product. Figure 3 illustrates concept 1 and describes each different part of the product. A headband is added to the speaking tube which enables the product to be worn by the users. The receivers have some small holes on it to improve air circulation and consequently reduce discomfort.

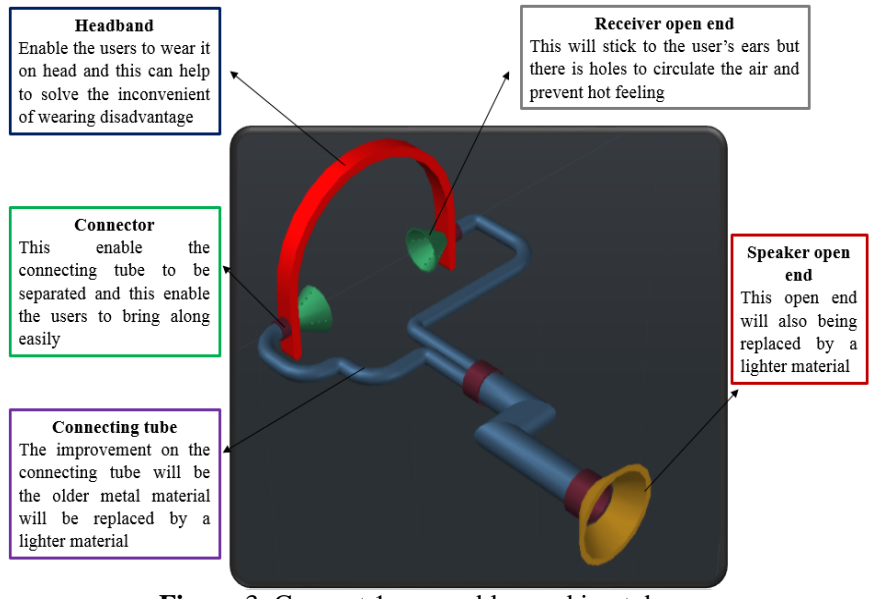

Figure 3: Concept 1 - wearable speaking tube

The speaking tube or the conversation tube is able to demonstrate satisfactory amplification effect while the head-held trumpet enables the product to be worn by the users. However, the trumpet does show a lower amplification effect due to the shape design of the sound entrance.

In combining these two different designs, the product will need to have a smaller head-held feature while the speaking tube should be shorter in length to reduce any inconvenience.

\subsection{Concept 2: Modified Wearable Speaking Tube}

Though concept 1 needed modification to reduce weight, it still requires two tubes to be connected to the users. This actually reduces amplification since sound travels from the speaker through a single tube but is then diffused into both receivers. Therefore, concept 2 may overcome this complication. Sound diffusion is prevented by channelling the sound to only one tube connecting the speaker and the receiver. Figure 4 illustrates concept 2 and describes each different part of the product. The design can also reduce the weight of the product. Furthermore, concept 2 possesses other added features which promote comfort. For example, the headband will be fitted with a sponge material for cushioning the user's head. There is also a protective cover that reduces interference from background noises and provides comfort at the same time. 


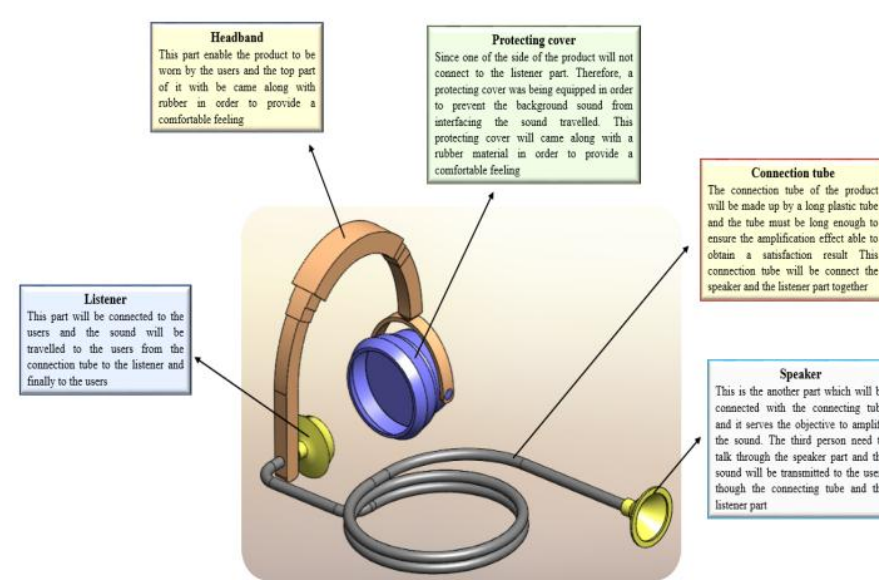

Figure 4: Concept 3 - modified wearable speaking tube

\subsection{Benchmarking and Concept Selection}

After both concepts have been characterised along with their benefits and disadvantages, benchmarking is complete. This needs to be done carefully in order to choose the better concept.

Table 1 shows the benchmark for both concepts based on differen characteristics. The higher the score, the better is the product. For the production cost, score 5 refers to the cheapest while score 1 refers to the most expensive. In terms of material accessibility, score 5 indicates that the material is easy to access/obtain while score 1 signifies that the material is scarce. In terms of weight, score 5 means the lightest while score 1 means the heaviest. In terms of product complexity, score 5 means the design is the simplest while score 1 means the design is the most complex. In terms of ergonomic features, score 5 represents the most ergonomic features while score 1 points to the least ergonomic features. Consequently, score 5 on manufacturability of the product means that the product can be easily manufactured or mass-produced, whereas score 1 means otherwise. The final characteristic that needs to be considered is the product's maintenance availability. Score 5 indicates that the product can be maintained and serviced with ease whereas score 1 means that the product's maintenance or servicing is difficult.

Table 1: Benchmark Result of Concept 1 and Concept 2

\begin{tabular}{|c|c|c|c|c|c|c|}
\hline Properties & Concept & \multicolumn{5}{|c|}{ Ranking } \\
\hline \multirow{2}{*}{$\begin{array}{c}\text { Cost of } \\
\text { production }\end{array}$} & $\begin{array}{c}\text { Concept } \\
1\end{array}$ & $\square 1$ & $\square 2$ & $\square 3$ & E4 & $\square 5$ \\
\hline & Concept & $\square 1$ & $\square 2$ & $\square 3$ & $\bar{\square} 4$ & $\square 5$ \\
\hline \multirow{2}{*}{$\begin{array}{c}\text { Material } \\
\text { Accessibility }\end{array}$} & Concept & $\square 1$ & $\square 2$ & $\square 3$ & $\square 4$ & $\overline{\underline{x}} 5$ \\
\hline & $\begin{array}{c}\text { Concept } \\
2\end{array}$ & $\square 1$ & $\square 2$ & $\square 3$ & $\square 4$ & $\overline{\square 5}$ \\
\hline \multirow{2}{*}{$\begin{array}{l}\text { Weight of the } \\
\text { product }\end{array}$} & $\begin{array}{c}\text { Concept } \\
1 \\
\end{array}$ & $\square \mathbf{1}$ & $\square 2$ & $\overline{\bar{x}_{3}}$ & $\square 4$ & $\square 5$ \\
\hline & $\begin{array}{c}\text { Concept } \\
2\end{array}$ & $\square 1$ & $\square 2$ & $\square 3$ & $\bar{\square} 4$ & $\square 5$ \\
\hline \multirow{2}{*}{$\begin{array}{l}\text { Complexity of } \\
\text { the product }\end{array}$} & $\begin{array}{c}\text { Concept } \\
1\end{array}$ & $\square 1$ & $\lfloor 2$ & $\square 3$ & $\square 4$ & $\square 5$ \\
\hline & $\begin{array}{c}\text { Concept } \\
2\end{array}$ & $\square 1$ & $\square 2$ & $\overline{\square 3}$ & $\square 4$ & $\square 5$ \\
\hline \multirow{2}{*}{$\begin{array}{c}\text { Ergonomic } \\
\text { features involved }\end{array}$} & $\begin{array}{c}\text { Concept } \\
1\end{array}$ & $\square \mathbf{1}$ & $\nabla 2$ & $\square 3$ & $\square 4$ & $\square 5$ \\
\hline & $\begin{array}{c}\text { Concept } \\
2\end{array}$ & $\square 1$ & $\square 2$ & $\bar{x} 3$ & $\square 4$ & $\square 5$ \\
\hline \multirow{2}{*}{ Manufacturability } & $\begin{array}{c}\text { Concept } \\
1\end{array}$ & $\square 1$ & $\square 2$ & $\nabla 3$ & $\square 4$ & $\square 5$ \\
\hline & $\begin{array}{c}\text { Concept } \\
2\end{array}$ & $\square 1$ & $\square 2$ & $\square 3$ & $\square 4$ & $\square 5$ \\
\hline \multirow{2}{*}{$\begin{array}{c}\text { Maintenance } \\
\text { availability }\end{array}$} & $\begin{array}{c}\text { Concept } \\
1\end{array}$ & $\square \mathbf{1}$ & $\square 2$ & $\bar{\Sigma} 3$ & $\square 4$ & $\square 5$ \\
\hline & $\begin{array}{c}\text { Concept } \\
2\end{array}$ & $\square 1$ & $\square 2$ & $\bar{x} 3$ & $\square 4$ & $\square 5$ \\
\hline \multirow{2}{*}{$\begin{array}{l}\text { Product } \\
\text { durability }\end{array}$} & $\begin{array}{c}\text { Concept } \\
1\end{array}$ & $\square 1$ & $\square 2$ & $\overline{\square 3}$ & $\square 4$ & $\square 5$ \\
\hline & $\begin{array}{c}\text { Concept } \\
2\end{array}$ & $\square 1$ & $\square 2$ & $\square 3$ & $\square 4$ & $\square 5$ \\
\hline \multirow{2}{*}{ Benchmark result } & $\begin{array}{c}\text { Concept } \\
1\end{array}$ & \multicolumn{5}{|c|}{ Total $=25 / 40$} \\
\hline & $\begin{array}{c}\text { Concept } \\
2\end{array}$ & \multicolumn{5}{|c|}{ Total $=29 / 40($ Selected $)$} \\
\hline
\end{tabular}

Since concept 2 scored higher after benchmarking, it is chosen as the design concept for this project. Concept 2 has shown advantages in terms of product characteristics, with better innovative features compared to concept 1 .

\section{Methodology}

\subsection{Failure Mode and Effect Analysis (FMEA)}

According to ASQ (American Society for Quality), failure mode and effect analysis (FMEA) is sometimes known as failure mode effects and criticality analysis (FMECA). Normally, performing FMEA requires different steps and sometimes, research and experiences may be required to perform it correctly [9]. Nowadays, producing a quality product is the mission and vision of many organizations. FMEA is necessary if the reliability and quality of a product need to be improved.

There are actually two main types of FMEA available. The Design FMEA is normally used to perform analysis on the functions of components or the subsystem, though it is sometimes used to analyse the main system. In contrast, the Process FMEA is mainly responsible for analysing the process of making a component, subsystem or main system. There are other types of FMEA which can analyse software, equipment and service. However, the Design FMEA will be used in this project to analyse the product.

\subsection{Temperature Experiment Test on Connecting Tube}

The connecting pipe attached to the non-electric hearing aid may melt under certain circumstances. When the product was left under a high temperature surrounding, the connecting pipe melted. This is due to the plastic tube used in the product, which could melt easily under high temperature. The product was left in an oven, set for a certain period of time, at high temperature.

A test was carried out in order to determine the melting temperature which had caused the connecting tube to melt. The connecting tubes were exposed under different temperature range and the melting status of the connecting tubes had been observed.

\subsection{Experimental Test on Suitable Connecting Tube Length}

The length of the connecting tube plays a very important role in the design of the non-electric hearing aid because it affects the performance of the product. A product with a very long connecting tube would inconvenience the users. However, if the tube was too short, it could reduce the amplification of the product since the amplification effect is based on the nature of the inverse square law of the surrounding. This inverse square law applies at the entrance of the speaker, when sound is captured into the connecting tube and causes resonance, subsequently allowing amplification. Therefore, a suitable length needs to be chosen in order to prevent operational failure. A test was carried out in order to determine the suitable length of the connecting tube.

This test was conducted using several different lengths of connecting tubes. The performance of the hearing aid was evaluated by using five different lengths of tubes. Upon evaluating the result, a suitable length for the connecting tube was selected for the design.

\section{Results and Discussion}

\subsection{Result of the Failure Mode and Effect Analysis (FMEA) Evaluation Test}

Failure Mode and Effect Analysis (FMEA) is important to evaluate the performance of the product. For this purpose, several tests needed to be carried out in order to gauge the performance more effectively. The tests carried out would help to prevent or reduce unwanted outcomes, thus might help to produce a more durable product. 
The FMEA was conducted for the product's headband and its plastic connecting tube. Possible failures that might occur on the headband and the connecting tube were listed. All the different failure modes were measured according to their severity by determining the risk priority number (RPN) values. These values were able to indicate the severity of a particular problem, and failure modes with higher RPN values need to be focused on because the possibility of failure in a particular area will be higher compared to the others.

For the headband, one possible failure would be the material fatigue, which may cause a serious problem to the non-electric hearing aid. Since it showed a high RPN value compared to the other failure modes, the bending cycling test should have been carried out to determine the number of bending cycle that the headband would be able to withstand. The bending cycling test would allow the designer to know the maximum stress that the headband can withstand. However, the bending cycle test was not performed since the product is just a $3 \mathrm{D}$ printed model. Further verification needs to be done in the future.

The FMEA was also performed on the connecting tube. One possible failure could occur if the connecting tube melts when left in a high temperature surrounding. In order to prevent this, an experiment is to be carried out to determine the range of the temperature in which the plastic connecting tube is able to withstand. From the experiment result, the designer can estimate the safe temperature in which the product is able to perform and the range of the result will be recorded in the manual provided. Another possible failure mode could be the incorrect length of connecting tube used. The connecting tube must be able to demonstrate satisfactory amplification effect without inconveniencing the user at the same time.

\subsection{Result of Temperature Experiment Test}

A test to determine the temperature range that the connecting tube can withstand is essential due to the material used. Made of plastic, the tube is lightweight but it should not be exposed to a hightemperature surrounding to prevent melting, which is a serious failure to the product. Table 2 below shows the result of the connecting tube melting status under different temperature (Celsius) exposures.

Table 2: Melting Status of Connecting Tube under Different Temperature Exposures

\begin{tabular}{|l|l|l|}
\hline Connecting tube length & Temperature $\left({ }^{\circ} \mathbf{C}\right)$ & Melting Status \\
\hline \multirow{5}{*}{$20 \mathrm{~cm}$} & 25 & No Melt \\
\cline { 2 - 3 } & 30 & No Melt \\
\cline { 2 - 3 } & 35 & No Melt \\
\cline { 2 - 3 } & 40 & Melt \\
\cline { 2 - 3 } & 45 & Melt \\
\hline
\end{tabular}

Based on the test performed, the material used for the connecting tube did not melt and was unaffected by room temperature ranging from $20{ }^{\circ} \mathrm{C}$ to $30^{\circ} \mathrm{C}$. Therefore, the product can be safely used at room temperature. When the tube was exposed to a higher temperature of $40{ }^{\circ} \mathrm{C}$ and above, some form of melting could be observed. Hence, it should be made clear under this product's specifications or manual that exposure to environments with high temperatures can cause the product to potentially fail.

\subsection{Result of the Experimental Test on Suitable Con- necting Tube Length}

The connecting tube plays a very important role in determining the product's performance. The tube needs to have an adequate length to ensure sufficient amplification effect. However, a longer connecting tube will only cause discomfort to users. Thus, a suitable length needs to be chosen based on the experiment's result. Table 3 shows a correlation between the connecting tube length and the product's amplification effect.
Table 3: Evaluation Result of Sound Level at Different Connecting Tube Length

\begin{tabular}{|c|c|c|}
\hline \multirow{2}{*}{$\begin{array}{l}\text { Length of the } \\
\text { connecting tube } \\
\text { (m) }\end{array}$} & \multicolumn{2}{|c|}{ The reading on the sound level meter (dB) } \\
\hline & Filter A & Filter C \\
\hline 0.5 & $\begin{array}{cr}\text { 1. } & 72.5 \\
\text { 2. } & 71.3 \\
\text { 3. } & 70.6 \\
\text { Average }= & 71.5\end{array}$ & $\begin{array}{rr}\text { 1. } & 76.5 \\
2 . & 77.3 \\
\text { 3. } & 76.3 \\
\text { Average }= & 76.7\end{array}$ \\
\hline 1.0 & 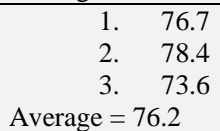 & $\begin{array}{rr}\text { 1. } & 78.6 \\
\text { 2. } & 77.8 \\
\text { 3. } & 79.3 \\
\text { Average }= & 78.6\end{array}$ \\
\hline 1.5 & $\begin{array}{cr}1 . & 77.6 \\
2 . & 79.5 \\
3 . & 74.8 \\
\text { Average }= & 77.3\end{array}$ & $\begin{array}{rr}1 . & 73.5 \\
2 . & 74.8 \\
3 . & 77.9 \\
\text { Average }= & 75.4\end{array}$ \\
\hline 2.0 & 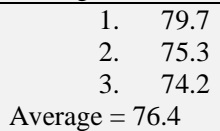 & $\begin{array}{rr}1 . & 71.5 \\
2 . & 77.3 \\
3 . & 79.8 \\
\text { Average }= & 76.2\end{array}$ \\
\hline 2.5 & 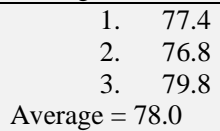 & $\begin{array}{rr}\text { 1. } & 73.5 \\
2 . & 79.8 \\
\text { 3. } & 78.3 \\
\text { Average }= & 77.2\end{array}$ \\
\hline
\end{tabular}

From the result obtained, the length of the connecting tube did not show a direct influence to the amplification effect of the product. Connecting tubes with the length of $0.5 \mathrm{~m}, 1.0 \mathrm{~m}, 1.5 \mathrm{~m}, 2.0 \mathrm{~m}$ and $2.5 \mathrm{~m}$ all showed an almost similar amplification effect. The range of the decibels recorded in filter $\mathrm{A}$ is from 71.5 to $78.0 \mathrm{~dB}$. Concurrently, filter $\mathrm{C}$ shows the range of 75.4 to $78.6 \mathrm{~dB}$. Therefore, the connecting tube length of 1.0 metre is able to reduce the inconvenience caused to the user while retaining a considerable good amplification effect.

\section{Conclusion}

A non-electric hearing aid has been fabricated and the product's performance has also been evaluated. The durability, reliability and functionality of the product can be examined after failure mode and effect analysis are performed on the product. Once the test has been carried out, the designer can be certain that the product is durable, reliable and is able to execute its amplification effect.

The design of a product is a never-ending process. Every product can be improved, innovated and redesigned to become better than before. The non-electric hearing aid designed for this project can be further improved to suit the users' needs. Further research and development are needed to continually enhance the performance of this non-electric hearing aid. This is important in helping people with hearing impairment, especially those who could not afford to own expensive electrical hearing aids. This non-electric hearing aid can actually assist them to rectify their hearing loss problem at a much lower cost.

\section{Acknowledgment}

The authors gratefully acknowledge the Research Management Centre and Collaborative Research and Innovation Centre of Multimedia University for their support in terms of the claim and public disclosure approvals pertaining to this research. The authors also thankfully acknowledge the Fundamental Research Grant Scheme (WBS. No.: MMUE/140072) provided by the Ministry of Education, Malaysia.

\section{References}

[1] S. R. Thayer and S. Joseph, Occupational Hearing Loss, 3rd ed. Boca Raton, Florida, United States: CRC Press, 2006. 
[2] K. Lysons, Understanding Hearing Loss. London: Jessica Kingsley, 1996.

[3] R. S. Tyler and D. J. Schum, Assistive Devices for Persons with Hearing Impairement, 1st ed. Boston, United States: Allyn \& Bacon, 1995.

[4] H. Dillon, Hearing Aids, 2nd ed. Sydney, New South Wales, Australia Boomerang Press, 2012.

[5] S. D. G. Stephens and J. C. Goodwin, "Non-Electric Aids to Hearing: A Short History," Audiology, vol. 23, no. 2, pp. 215-240, 1984.

[6] D. M. Ross, "Hearing Aid Troubleshooting", http://goo.gl/p4hqEM. 1999. (Accessed on 2 October 2016).

[7] K. Bouton, "Why We Don't Wear Hearing Aids", https://goo.gl/dgp5xy. 2013. (Accessed on 2nd Octocber 2016).

[8] B. G. Glaser, "Conceptualization: On Theory and Theorizing Using Grounded Theory " International Journal of Qualitative Methods vol. 1, no. 2, pp. 1-31, 2002.

[9] N. R. Tague, The Quality Toolbox, 2nd ed. Milwaukee, Wisconsin, USA: ASQ Quality Press, 2004. 